\title{
Molecular characterization of an operon, cueAR, encoding a putative P1-type ATPase and a MerR-type regulatory protein involved in copper homeostasis in Pseudomonas putida
}

\author{
Vellaichamy Adaikkalam and Sanjay Swarup
}

\begin{abstract}
Author for correspondence: Sanjay Swarup. Tel: +65 874 7933. Fax: +65 7792486. e-mail:dbsss@nus.edu.sg
\end{abstract}

Department of Biological Sciences, Science Drive 4 National University of Singapore, Singapore 117543

\begin{abstract}
The authors have characterized a chromosomally localized two-gene operon, cueAR, which encodes a putative P1-type ATPase, CueA, and a MerR-type metalloregulatory protein, CueR, in Pseudomonas putida PNL-MK25. Disruption of cueAR by the insertion of mini-Tn5:: gfp into the wild-type strain led to a mutant strain with a sixfold reduction in its tolerance to copper; however, the tolerance of this mutant strain to the other seven related transition metals tested was not affected. The sensitivity of the mutant strain was attributed to a higher level of accumulation of intracellular copper, suggesting the involvement of CueA in copper export. Insertion of the cloned cueAR operon into the copper-sensitive mutant strain fully restored its tolerance to copper. cueA:: gfp expression studies confirmed that the cueAR operon was transcriptionally regulated by copper and CueR. Studies done on the mutant strain complemented with cue $R$ and cueA revealed partial functional redundancy of cueA and cueR, respectively, in copper tolerance. Thus, the results of this study clearly suggest the involvement of cueAR in copper homeostasis in P. putida.
\end{abstract}

Keywords: copper tolerance, CPx-type ATPase, mini-Tn5::gfp mutagenesis

\section{INTRODUCTION}

Metals play a vital role in biological systems. It is estimated that over $50 \%$ of all proteins are metalloproteins and that about a third of all structurally characterized proteins contain metals (Degtyarenko, 2000). Copper is one such element that is required for a number of important cellular enzymes such as cytochrome oxidase, superoxide dismutase, ascorbate oxidase, ceruloplasmin, laccase, lysyl oxidase and other oxygenases (Camakaris et al., 1999; Buffoni \& Ignesti, 2000; Dameron \& Harrison, 1998). However, excess cellular copper can react non-specifically with cysteine and histidine residues in proteins and disrupt their activity. Copper is also known to produce reactive oxygen species, which can lead to cellular damage (Dameron \& Harrison, 1998). Cells have to maintain

Abbreviations: GFP, green fluorescent protein; MIC, minimal inhibitory concentration.

The GenBank accession number for the sequence reported in this paper is AF390440. intracellular copper at subtoxic levels, as it is extremely toxic at supra-optimal concentrations.

Eukaryotic and prokaryotic systems possess several mechanisms for copper homeostasis, such as reduced influx, facilitated efflux, sequestration and modification (Camakaris et al., 1999; Dameron \& Harrison, 1998). In eukaryotes, many transition metals, including copper, are generally sequestered by small cysteine-rich proteins termed metallothioneins. Apart from metallothioneins, eukaryotes also possess transporters such as the P-type ATPases for the facilitated efflux of these metals. P-type ATPases form a phospho-aspartate intermediate in the ATP-driven cation-transport cycle and contain conserved domains for phosphorylation, ATP binding and phosphatase activity (Lutsenko \& Kaplan, 1995). P-type ATPases involved in metal-ion transport contain additional motifs such as a conserved HP dipeptide, a transmembrane CPx motif and one or more aminoterminal metal-binding domains (Lutsenko \& Kaplan, 1995; Solioz \& Vulpe, 1996). These P-type ATPases are called P1-type ATPases or CPx-type ATPases. Examples of eukaryotic copper-transport P1-type ATPases include 
CaCRP1 of Candida albicans (Weissman et al., 2000) and the Menkes disease and Wilson disease proteins of human origin (Bull \& Cox, 1994).

Prokaryotic copper-transport systems generally use copper-binding proteins and/or P1-type ATPases that are encoded by plasmids or the chromosome. P1-type ATPases have been described for bacterial coppertransport systems in many genera, including Enterococcus (Odermatt et al., 1993), Helicobacter (Bayle et al., 1998) and Escherichia (Rensing et al., 2000). Previous studies on Pseudomonas spp. have focused mainly on the high levels of copper resistance seen in strains recovered from agricultural soils with a history of copper fungicide applications. One of the best characterized determinants of copper resistance in prokaryotes is the $\operatorname{cop} A B C D$ operon system that resides on a $35 \mathrm{~kb}$ plasmid of the copper-resistant strain of Pseudomonas syringae pv. tomato PT23.2 isolated from Californian tomato fields (Mellano \& Cooksey, 1988). This operon, encoding copper-binding periplasmic and membrane proteins, is similar in structure and function to the other known plasmid-encoded determinant of copper resistance, the $p c o$ operon identified on a plasmid from Escherichia coli (Tetaz \& Luke, 1983). Similarly, chromosomal determinants of copper tolerance have been cloned from many Pseudomonas strains and these have been found to have similarity either to the plasmidencoded cop operon or to the genes involved in cytochrome $c$ biogenesis in E. coli (Cooksey et al., 1990; Vargas et al., 1995; Yang et al., 1996). Recently, a copper-inducible gene was identified in the chromosome of Pseudomonas fluorescens and it was shown to affect the copper tolerance of this bacterium (Tom-Petersen $e t$ al., 2001). A partial sequence of this chromosomal gene showed similarity to putative P-type ATPases.

Here, we show the involvement of a P1-type ATPase and a MerR-type regulatory protein encoded by a single operon in copper homeostasis in Pseudomonas putida. Further evidence shows that this chromosomally located operon, cueAR, is regulated by copper and the regulator, and that both members of this operon are partially functionally redundant.

\section{METHODS}

Strains and plasmids. The bacterial strains and plasmids used in this study are described in Table 1. Pseudomonas putida PNL-MK25 is an antibiotic-resistant derivative of the plantgrowth-promoting rhizobacterial strain ATCC 39169 and is referred to here as the wild-type strain. Strain PNL-MK25 was used as the recipient in conjugation experiments. The suicide delivery vector pAG408 carrying mini-Tn5::gfp was intro-

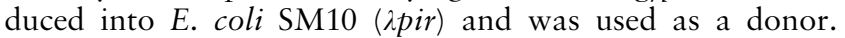
Cloning vectors pUC18 and $\mathrm{pBSIISK}^{+}$were used for propagation in E. coli DH5 $\alpha$. The shuttle vector pGB1 was used for complementation studies.

Growth media. P. putida and E. coli were grown routinely in LB medium at 30 and $37^{\circ} \mathrm{C}$, respectively, with constant shaking at 240 r.p.m. Bacterial conjugations and selection of transconjugants were done on tryptic soy agar (TSA) plates, as described previously (Pillai \& Swarup, 2002). Screening of the mutants was performed on Stanier's mineral (SM) minimal medium (Stanier et al., 1966) supplemented with $0.5 \%$ (v/v) glycerol and appropriate antibiotics. For gene-expression analyses, mannitol/glutamate/yeast extract (MGY) medium (Bender \& Cooksey, 1986) was used. The antibiotics chloramphenicol, gentamicin, kanamycin, tetracycline and ampicillin were used at concentrations of 30,20,30,60 and $100 \mu \mathrm{g} \mathrm{ml}^{-1}$, respectively, in TSA medium, and at concentrations of 15, 10, 15, 40 and $75 \mu \mathrm{g} \mathrm{ml}^{-1}$, respectively, in SM and MGY media.

Transposon mutagenesis and screening of mutants. For miniTn $5:: g f p$ mutagenesis, biparental mating was performed between the donor E. coli strain and the recipient $P$. putida strain. Patch-matings of $4 \mathrm{~h}$ duration were harvested in saline and spread onto TSA plates that contained chloramphenicol, gentamicin and kanamycin. A conjugation frequency of $2 \times 10^{-3}$ (recipient cell $)^{-1}$ was obtained while the spontaneous mutation frequency was $1 \times 10^{-7}$ (recipient cell) ${ }^{-1}$. Insertion of mini-Tn $5:: g f p$ was checked by colony PCR, in which transconjugant colonies that had been grown for $36 \mathrm{~h}$ were used as templates together with primers for the amplification of $g f p$ (forward, 5'-TAGATGGTGATGTTAATGGGC-3'; reverse, 5'-GCCATGTGTGTAATCCCAGCAG-3'). The PCR protocol used was: 30 cycles of denaturation at $95^{\circ} \mathrm{C}$ for $40 \mathrm{~s}$, annealing at $58^{\circ} \mathrm{C}$ for $40 \mathrm{~s}$ and extension at $72{ }^{\circ} \mathrm{C}$ for $1 \mathrm{~min}$. Taq DNA polymerase (Promega) was used to catalyse the reaction. Of the 120 randomly chosen colonies that were tested, all were positive for amplification of $g f p$ (data not shown). Approximately 9000 transconjugants carrying $g f p$ transcriptional fusions were screened by replica-plating for increased green fluorescence when grown in the presence of transition metals on SM medium (Stanier et al., 1966). One of the eight putative mutants that showed the highest response to transition metals in our preliminary studies was chosen for further analyses. This mutant was designated CEM1 (copper export mutant), based on the results shown later.

Metal-sensitivity assays. The minimal inhibitory concentration (MIC) of each of the transition metals tested was estimated by streaking single colonies from MGY plates onto plates containing varying concentrations of transition metal ions, namely, $\mathrm{Hg}^{2+}, \mathrm{Ag}^{+}, \mathrm{Zn}^{2+}, \mathrm{Fe}^{2+}, \mathrm{Cu}^{2+}, \mathrm{Ni}^{2+}, \mathrm{Co}^{2+}$ and $\mathrm{Cd}^{2+}$. The lowest metal concentration that inhibited growth after incubation for $60 \mathrm{~h}$ at $30^{\circ} \mathrm{C}$ was recorded as the MIC. Sensitivity of the cells to copper in MGY broth was checked as described below in 'Complementation studies'.

DNA manipulations and analyses. Routine recombinant DNA techniques were performed as described by Sambrook et al. (1989). Genomic DNA was isolated from the Pseudomonas cells as described previously (Syn \& Swarup, 2000). The genomic DNA of CEM1 cells was digested with BglII and $K p n \mathrm{I}$, and Southern-blot analysis was done. Full-length DNA probes for the $g f p$ and gentamicin-resistance genes were obtained from pAG408 (Suarez et al., 1997). Digoxigeninlabelling was done according to the manufacturer's protocol (Boehringer Mannheim). BglII and KpnI cut the transposon, leaving the kanamycin- and gentamicin-resistance genes intact (Suarez et al., 1997). The transposon-flanking upstream genomic DNA from the mutant strain was cloned using $B g l \mathrm{II}$, and downstream genomic DNA was cloned using KpnI. After cloning of these flanking DNA fragments into the vectors pUC18 and pBSIISK +, further subcloning of the transposonflanking DNA was done to sequence $3 \mathrm{~kb}$ of the upstream and $3.3 \mathrm{~kb}$ of the downstream region. Vector primers and genespecific primers were used to sequence the cloned fragments. Automated DNA sequencing was performed with the BigDye Terminator Cycle Sequencing Ready Reaction DNA Se- 
Table 1. Bacterial strains and plasmids used in this study

\begin{tabular}{|c|c|c|}
\hline Strain/plasmid & Relevant characteristics* & Source/reference \\
\hline \multicolumn{3}{|l|}{ E. coli } \\
\hline 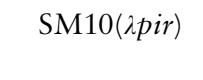 & $\begin{array}{l}\text { thil thrl leuB6 supE44 tonA21 lacY1 recA-: RP4-2-Tc:: Mu; a derivative of } \\
\text { E. coli strain C600; } \mathrm{Km}^{\mathrm{r}}\end{array}$ & Suarez et al. (1997) \\
\hline $\mathrm{DH} 5 \alpha$ & supE44 $\Delta($ lacU169) ( $\phi 80$ lacZ $\Delta \mathrm{M} 15)$ hsdR17 recA1 endA1 gyrA96 thi-1 relA1 $\mathrm{F}^{-}$ & Gibco-BRL \\
\hline \multicolumn{3}{|l|}{ P. putida } \\
\hline PNL-MK25 & $\begin{array}{l}\text { Derivative of plant-growth-promoting rhizobacterial strain ATCC } 39169 ; \\
\text { referred to as the wild-type strain in this article; } \mathrm{Cm}^{\mathrm{r}}, \mathrm{Rif}^{\mathrm{r}}\end{array}$ & Mark Kingsley, PNNL, USA \\
\hline CEM1 & $\begin{array}{l}\text { Mini-Tn5::gfp cassette inserted into copper-transporting ATPase-encoding } \\
\text { chromosomal locus in the wild-type strain; } \mathrm{Km}^{\mathrm{r}}, \mathrm{Gm}^{\mathrm{r}}\end{array}$ & This study \\
\hline \multicolumn{3}{|l|}{ Plasmid } \\
\hline pAG408 & $\begin{array}{l}\text { Suicide delivery promoter-probe vector carrying the mini-Tn } 5:: g f p \text { cassette } \\
(5.75 \mathrm{~kb}) ; \mathrm{Ap}^{\mathrm{r}}, \mathrm{Km}^{\mathrm{r}}, \mathrm{Gm}^{\mathrm{r}}\end{array}$ & Suarez et al. (1997) \\
\hline pUC18 & Cloning vector $(2 \cdot 7 \mathrm{~kb}) ; \mathrm{Ap}^{\mathrm{r}}$ & Vieira \& Messing (1982) \\
\hline pBSIISK + & Cloning vector $(3.0 \mathrm{~kb}) ; \mathrm{Ap}^{\mathrm{r}}$ & Stratagene \\
\hline pGB1 & $\begin{array}{l}\text { Shuttle vector for E. coli and Psendomonas spp. carrying a stabilizing fragment } \\
(6.3 \mathrm{~kb}) ; \mathrm{Ap}^{\mathrm{r}}, \mathrm{Tc}^{\mathrm{r}}\end{array}$ & Bloemberg et al. (1997) \\
\hline pGBcueAR & $\begin{array}{l}\text { pGB1 carrying a } 3.6 \mathrm{~kb} \text { genomic fragment of the full-length } c u e A R \text { locus; } \mathrm{Ap}^{\mathrm{r}} \text {, } \\
\mathrm{Tc}^{\mathrm{r}}\end{array}$ & This study \\
\hline pGBcueA & $\begin{array}{l}\text { pGB1 carrying a } 3.4 \mathrm{~kb} \text { genomic fragment of full-length cueA and truncated } \\
\text { cueR; } \mathrm{Ap}^{\mathrm{r}}, \mathrm{Tc}^{\mathrm{r}}\end{array}$ & This study \\
\hline pGBcueR & $\begin{array}{l}\text { pGB1 carrying a } 0.45 \mathrm{~kb} \text { genomic fragment of } c u e R \text { fused with lac Z promoter } \\
\text { of the vector; } \mathrm{Ap}^{\mathrm{r}}, \mathrm{Tc}^{\mathrm{r}}\end{array}$ & This study \\
\hline
\end{tabular}

$* \mathrm{Cm}^{\mathrm{r}}$, Chloramphenicol-resistant; $\mathrm{Gm}^{\mathrm{r}}$, gentamicin-resistant; $\mathrm{Km}^{\mathrm{r}}$, kanamycin-resistant; Rif ${ }^{\mathrm{r}}$, rifampicin-resistant; Tc ${ }^{\mathrm{r}}$, tetracyclineresistant; $\mathrm{Ap}^{\mathrm{r}}$, ampicillin-resistant.

quencing Kit (Applied Biosystems). Primers containing an $X b a I$ site (cueAR-F, 5'-CGTCTAGAGCGATGGCAAGGTCAAGTTC-3', and cueAR-R, 5' -CCTCTAGAGCTGTTCCACGGCATTCCC-3' ; restriction site shown in bold) were designed to amplify a $3.6 \mathrm{~kb}$ fragment that encoded the entire cueAR operon along with its promoter. A proof-reading-type Vent DNA polymerase (New England Biolabs) was used to catalyse the reaction. The PCR protocol used was : 30 cycles of denaturation at $95^{\circ} \mathrm{C}$ for $40 \mathrm{~s}$, annealing at $60^{\circ} \mathrm{C}$ for $40 \mathrm{~s}$ and extension at $76^{\circ} \mathrm{C}$ for 3 min $40 \mathrm{~s}$. Plasmid pGBcueAR was constructed by subcloning the $3.6 \mathrm{~kb}$ fragment into the $\mathrm{XbaI}$ site of the shuttle vector pGB1 (Bloemberg et al., 1997). Using this construct, pGBcueA was generated by excising a $0 \cdot 2 \mathrm{~kb}$ DNA fragment from the $3^{\prime}$ end of $c u e R$ by using $S a c I$, thereby truncating cueR. The second gene of the cueAR operon, cueR, was amplified with an upstream primer containing an EcoRI site (CueR-F，5'-AGAATTCCTGatgGCGCTGTCGAG-3'; restriction site in bold, ATG of cueR in lower-case) and the downstream primer cueAR-R that was used for amplification of cueAR. The cueR gene fragment was cloned into the EcoRI and $X b a \mathrm{I}$ sites of pGB1 to construct $\mathrm{pGB} c u e R$, resulting in cueR expression from the lacZ promoter. In Pseudomonas, the shuttle vector pGB3 (a derivative of pGB1) allows the expression of genes under the control of the lac promoter without the need for any exogenous inducer (Bloemberg et al., 1997). Hence, no inducer was added in the expression studies with cells containing pGBcueR. The secondary structure of a $50 \mathrm{bp}$ RNA sequence of the $c u e A-c u e R$ junction was predicted by using the Vienna RNA package (Hofacker et al., 1994).

Complementation studies. The pGBcueAR, pGBcueA and pGBcueR constructs were introduced into cells of the coppersensitive $P$. putida CEM1 strain by electroporation, as described by Bloemberg et al. (1997). Cells of the wild-type strain, the CEM1 strain and the CEM1(pGBcueAR) strain were grown in MGY broth to an $\mathrm{OD}_{600}$ of $0 \cdot 32$, before the addition of the appropriate amounts of copper sulphate from a $100 \mathrm{mM}$ stock solution to the medium. Functional complementation was studied by monitoring the growth of the cells for another $12 \mathrm{~h}$ at $30^{\circ} \mathrm{C}$ with constant shaking (240 r.p.m.). For spectrophotometric measurements, the cells that had been grown in MGY broth were pelleted by centrifugation and resuspended in PBS (Sambrook et al., 1989). For each experiment four replicates were maintained. For the CEM1 cells carrying pGBcueA and $\mathrm{pGB} c u e R$, complementation was checked by MIC analysis on MGY agar plates, as described in 'Metal-sensitivity assays'.

Gene-expression analysis. The $c u e A R$ transcriptional fusion with $g f p$ (cueA::gfp) was used to study gene expression. Two methods were employed to study the production of green fluorescent protein (GFP). In the first method, the CEM1 cells were grown in MGY broth supplemented with varying levels of copper; GFP production by these cells was visualized under a confocal laser microscope (Olympus Fluoview 300 LSM). In the second method, the CEM1 strain and the CEM1 (pGBcueR) strain were grown in MGY broth to an $\mathrm{OD}_{600}$ of about $0 \cdot 32$, before the addition of various amounts of copper sulphate to the medium. Based on the results from our preliminary studies, the cells were incubated for $4 \mathrm{~h}$ at $30^{\circ} \mathrm{C}$ with constant shaking (240 r.p.m.). The cells were pelleted by centrifugation and resuspended in filter-sterilized PBS for measurement of their GFP fluorescence by flow cytometry (Coulter Epics Elite; Beckman Coulter). For each experiment, data from 30000 events were collected and three replicates were maintained. 
Copper-accumulation analysis. Copper sulphate was added at different concentrations to the bacterial cultures when they had reached an $\mathrm{OD}_{600}$ value of 0.32 in MGY medium. The cells were then incubated again and samples were taken from the cultures at various time intervals $(0,2,4,6$ and $8 \mathrm{~h})$. These samples were pelleted, and the copper content of the pelleted cells was analysed using an Atomic Absorption Spectrophotometer (model A6800F; Shimadzu) as described by Beard et al. (1997). The dry weights of the cells were obtained after the pellets had been freeze-dried.

PFGE. To ascertain the location of the cueAR region, Southernblot analysis with the transposon-specific probe was performed on the mutant strain DNA after analysis of total DNA by PFGE. Alkaline lysis (Sambrook et al., 1989) and a megaplasmid preparation (Casse et al., 1979) were done to check for the presence of any indigenous plasmid(s). Later, PFGE was carried out to resolve the intact total DNA. Sample preparation was done based on the method described by Sambrook et al. (1989). In brief, agarose plugs were prepared by mixing $1 \mathrm{ml}$ of Pseudomonas cells suspended in TE $(10 \mathrm{mM}$ Tris/HCl, $1 \mathrm{mM}$ EDTA) with $1 \mathrm{ml}$ of $1 \%$ low-gellingtemperature agarose prepared in TE containing $50 \mu \mathrm{g}$ lysozyme $\mathrm{ml}^{-1}$. The plugs were treated with proteinase $\mathrm{K}$ before they were loaded into the wells of the PFGE gel prepared with ultra-pure DNA-grade agarose (Bio-Rad). Gel electrophoresis was carried out in $0.5 \times \mathrm{TBE}$ at $140 \mathrm{~V}$ for $36 \mathrm{~h}$ at $1 / 25$ with a $1: 1$ pulse ratio on a CHEF-DR-II apparatus (Bio-Rad). Commercially available yeast chromosomal DNA plugs (Sigma) were used for sizing the DNA fragments. Following electrophoresis, the gel was stained with ethidium bromide, visualized under a UV light and photographed. The gel was then used for Southern-blot analysis. A probe for $g f p$ was prepared by using the DIG High-Prime Labelling and Detection Kit (Boehringer Mannheim), as per the manufacturer's protocol.

\section{RESULTS}

\section{Sensitivity of the CEM1 strain to copper}

A mutant strain of P. putida PNL-MK25, designated CEM1, which carried a transposon insertion in a gene responsive to transition metals was identified by genetic screening. To test the sensitivity and specificity of this strain towards a number of soft metal ions, the MICs of a number of different metal ions were determined by growing the strain on MGY agar plates containing varying concentrations of these ions. The $P$. putida wildtype and CEM1 strain had similar MIC values for the seven transition metals tested (mercury, silver, zinc, iron, nickel, cobalt and cadmium; data not shown). Differences in their MIC values were only seen for copper. The MIC of copper sulphate for the wild-type strain was $400 \mu \mathrm{M}$, whereas the MIC of copper sulphate for the CEM1 strain was $65 \mu \mathrm{M}$. Hence, it was inferred that the copper tolerance of the P. putida CEM1 strain was altered when compared to the wild-type strain, PNL-MK25.

\section{Characterization of the cueAR region}

Southern-blot analysis of CEM1 genomic DNA that had been digested with BglII and KpnI showed single bands of 13.0 and $12.5 \mathrm{~kb}$ (data not shown) in size, respectively, indicating a single insertion of the transposon. Sequencing of the $6.3 \mathrm{~kb}$ DNA region surrounding the transposon insertion site revealed six ORFs and also showed that the transposon had inserted at nucleotide position 79 of a $2 \cdot 4 \mathrm{~kb}$ ORF (Fig. 1a). The insertion site had a signature 9 bp duplication of the sequence $5^{\prime}$-GGCATGACC-3'. Results of a BLAST search of the $2 \cdot 4 \mathrm{~kb}$ ORF product against the GenBank database showed that the predicted protein of 797 aa had a high degree of similarity to several functionally characterized coppertransport ATPases, including CopA of E. coli (Rensing et al., 2000), CopA of Enterococcus hirae (Odermatt et al., 1993) and the Wilson and Menkes disease proteins of human origin (Bull \& Cox, 1994). Based on sequence similarity and functional characteristics (shown later) similar to previously characterized copper-transport proteins, the $2 \cdot 4 \mathrm{~kb}$ ORF of $P$. putida was named cue $A$ (for $\underline{\mathrm{Cu}}$ export ATPase $\underline{\mathrm{A}}$ ). The percent identities of the $P$. putida CueA amino-acid sequence with CopA of Escherichia coli, CopA of Enterococcus hirae, the human Wilson disease protein ATP7B, PA3920 of P. aeruginosa (accession no. AE004809), plasmid pPaCu1OrfG from $P$. syringae (accession no. AB044355) and ActP of Sinorbizobium meliloti (accession no. AF129004) were 36, 39, 32, 68, 60 and 38, respectively. $P$. putida CueA is predicted to contain at least eight potential transmembrane regions, based on its hydropathy plot and its similarity to other characterized bacterial copper ATPases (Fig. 2). The CPx motif (CPC) and other domains conserved in all P-type ATPases are present in CueA (Fig. 2).

cueA is the first gene of an operon that contains a downstream gene that encodes a helix-turn-helix-type DNA-binding regulatory protein (Fig. 1a); this regulatory gene is designated $c u e R$ (for $\mathrm{Cu}$ export regulator). The predicted CueR protein consists of 137 aa and shows a high degree of similarity to the MerR family of proteins, including the recently published Escherichia coli copper-transport regulator CueR (Fig. 3a; Outten et al., 2000; Stoyanov et al., 2001).

The cueA-cueR junction carries a -1 shift in the reading frame for the initiation of CueR translation with respect to its cue $A$ reading frame (Fig. 1a). The putative translational termination signal (TGA) of cueA is part of the translational start (ATG) signal of cueR. The GAGGA Shine-Dalgarno consensus sequence of $c u e R$ is located in the $8 \mathrm{bp}$ preceding the ATG of cueR. The predicted RNA secondary structure of the cueA-cueR junction shows a stable hairpin loop (Fig. 4). In such a structure, the Shine-Dalgarno sequence and the overlapping translational start codon occur at locations that are inaccessible to free ribosomes for translation. The cueAR operon has a promoter of approximately $200 \mathrm{bp}$ in size and possesses many putative DNA-binding sites for regulatory proteins. A cop box consisting of an $8 \mathrm{bp}$ inverted repeat is found at the same location (between -10 and -35$)$ as that described for the E. coli copA promoter, $\mathrm{P}_{\text {copA }}$ (Fig. 1c; Outten et al., 2000; Stoyanov et al., 2001). Six nucleotides within the consensus cop box that are known to be the binding sites for the E. coli 
(a)

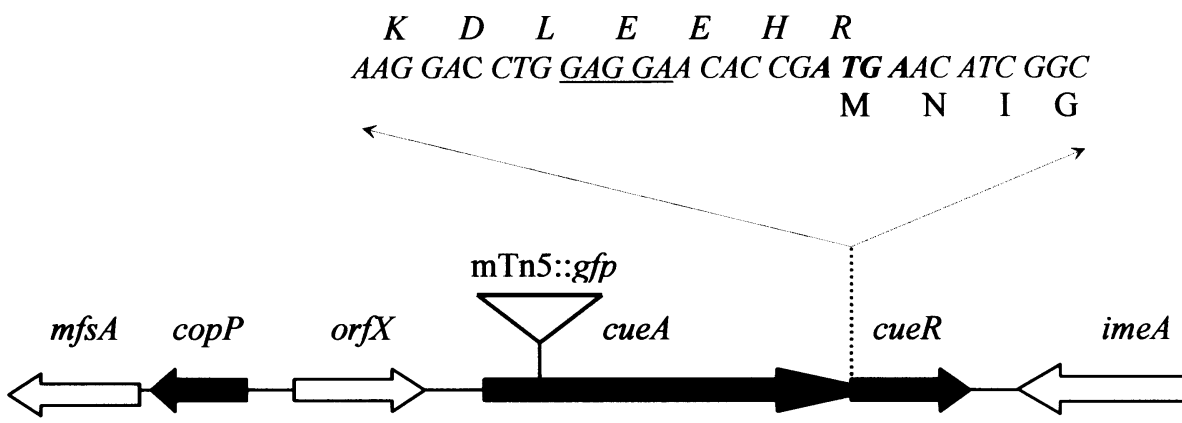

(b)

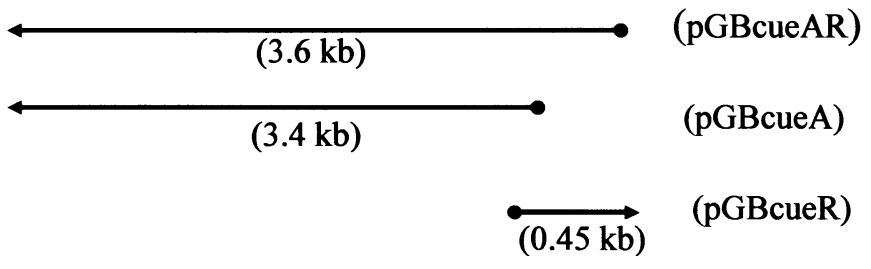

\section{MIC of copper}

$400 \mu \mathrm{M}$

$375 \mu \mathrm{M}$

$275 \mu \mathrm{M}$

(c)

PcopA_E ATGTCTAATCCT-GATGCAAATCGAGCCGATTTTTTAATCTTTACG--G--ACTTTTA-CCCGCCTGGTTTATTAATTTPcopP_P AT-TCCAGTCATTGATGCAT-----GCAGCTTGGCCGAGCGCGACGCCG--AATGCCAGCCCGGCAGTTTTTCGCAGAA-

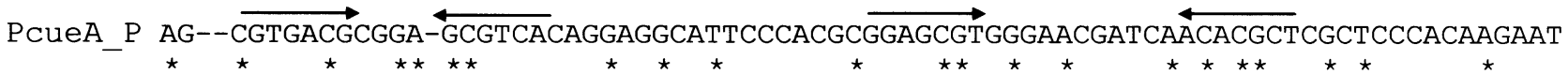

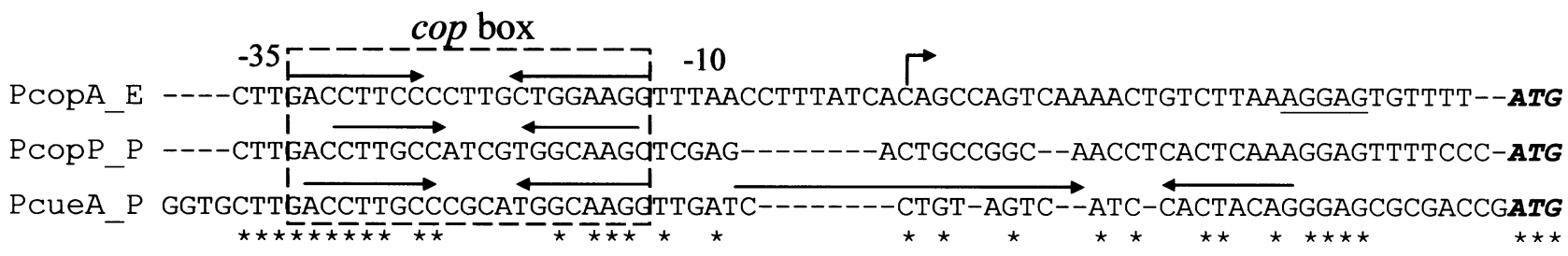

Fig. 1. The cueAR locus. (a) Organization of the genes and ORFs in the cueAR region is indicated by arrows. The insertion site of the mini-Tn5::gfp fusion, near the $5^{\prime}$ end of cueA, is indicated by a triangle. The DNA and amino-acid sequence of the cueA-cue $R$ junction is shown at the top of (a). The putative Shine-Dalgarno sequence (underlined) and the overlapping DNA sequences (bold) are also shown within the DNA sequence. (b) Regions of the cueAR operon included in the complementation constructs are shown as straight lines. The arrows indicate the orientation of the gene with respect to the promoter of the vector. The MICs of copper for the strains carrying the respective constructs are given at the right-hand side of the figure. (c) Sequence comparison of the promoter region of $E$. coli copA (PcopA_E) with the promoter regions of $P$. putida copP (PcopP_P) and cueAR (PcueA_P). The inverted repeats are indicated by straight arrows; the transcriptional start site is indicated by a bent arrow. The $E$. coli CueR binding site in PcopA_E, and its corresponding site in the $P$. putida promoters, is indicated by the cop box. The predicted translational start points are in bold. Asterisks below the alignment indicate nucleotides conserved among the three sequences.

copA transcriptional activator, $\mathrm{CueR}$, are also present in P. putida $\mathrm{P}_{\text {cue } A}$. However, in comparison to E. coli $\mathrm{P}_{\text {copt }}$, the $P$. putida promoter carries additional inverted repeats both upstream and downstream of the cop box (Fig. 1c).

Among the other four ORFs found around the cueAR region, the most notable is the gene designated as $\operatorname{copP}$, with its direction of transcription away from the cueAR operon (Fig. 1a). The copP gene encodes a putative homologue of the periplasmic metal-binding protein MerP of the mercury-transport system (Lund \& Brown, 1987), the CopZ chaperone of the Enterococcus hirae copper-transport system (Odermatt \& Solioz, 1995) and the CopP protein of Helicobacter pylori (Bayle et al., 1998). P. putida CopP contains a conserved heavymetal-associated domain at its $\mathrm{N}$ terminus (Fig. 3b), and the promoter of $\operatorname{copP}$ carries a cop box (Fig. 1c). The other ORFs flanking the cueAR region-orf $X, m f s A$ and imeA (Fig. 1a)-showed similarities to a hypothetical 


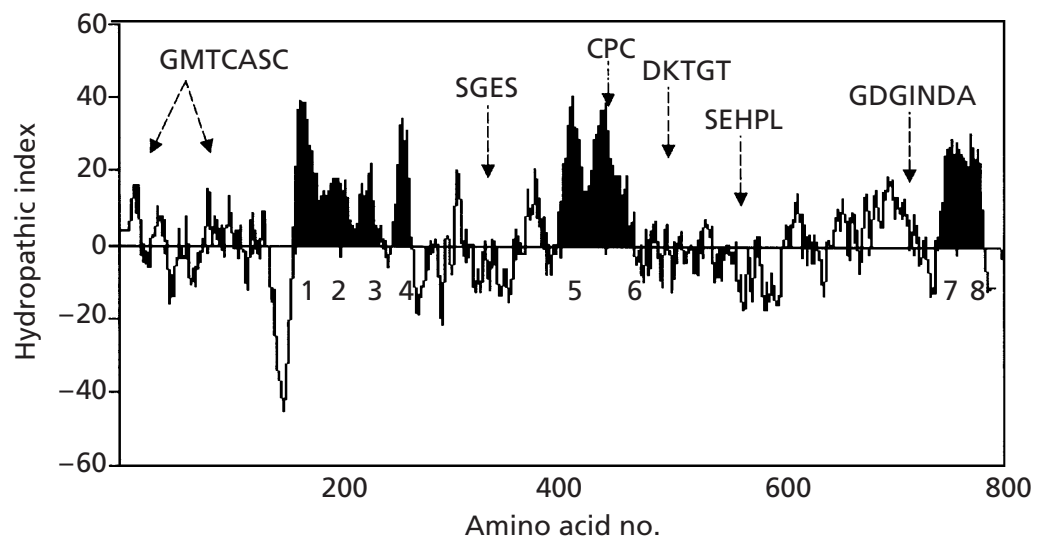

Fig. 2. Kyte and Doolittle hydropathy plot for CueA. Transmembrane regions are numbered below the traces. Two metalbinding domains, GMTCASC, are indicated by arrows. Conserved sequence motifs of P1type ATPases found in CueA are: SGES, phosphatase domain; CPC, ion-translocation domain; DKTGT, aspartyl kinase domain; SEHPL, unknown function (conserved HP dipeptide); GDGINDA, ATP-binding domain.

(a) H-T-H motif
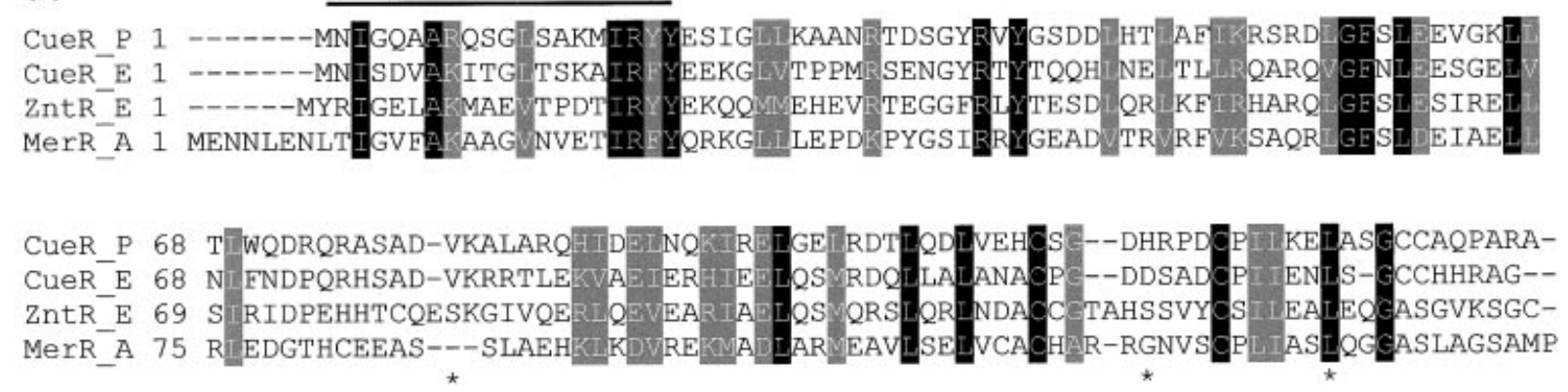

(b)

CopP

PA3520

CopZ

HMA domain

Merp

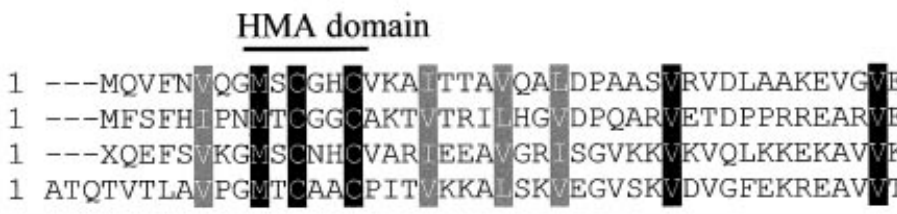

VESALS---ADQVIA IR E EY
VESTLD---KHAFLE LS AGY
VKFDEANVQATEICQ IN I
WTFDDTKASVQKLTKMTA AgY

EVKLVPEGR-QAEVIPSSVKQ

Fig. 3. Sequence alignments of the predicted CueR and CopP proteins of $P$. putida with similar proteins. The CLUSTAL W and BOXSHADE programs were used to generate the alignments. (a) Alignment of CueR of $P$. putida (CueR_P) with other members of the MerR family of heavy-metal-regulator proteins. The conserved helix-turn-helix (H-T-H) DNA-binding motif is shown. The mercury-binding cysteines of MerR are indicated by asterisks. SWISS-PROT accession numbers for the sequences are: CueR_E (of E. coli), P77565; ZntR_E (of E. coli), P36676; MerR_A (of P. aeruginosa Tn501), P06688. (b) Similarity of predicted CopP sequence to related proteins. The conserved heavy-metal-associated (HMA) domain is shown. The GenBank accession numbers for the proteins are: PA3520 (of $P$. aeruginosa), AE004772; CopZ (of Enterococcus hirae), Q47840; MerP (of Shigella flexneri), P04129.

ORF, PA3576, of $P$. aeruginosa (http://www.pseudomonas.com), sequences for major facilitator superfamily proteins and integral membrane efflux proteins.

\section{Chromosomal localization of the cueAR region}

Plasmid analysis was performed on the wild-type strain and on the CEM1 strain, to check for the presence of any indigenous plasmid(s) that could harbour the cueAR locus. Neither the alkaline lysis nor the mega-plasmid preparations yielded any plasmid DNA that was detectable in ethidium-bromide-stained agarose gels (data not shown). Intact genomic DNA from the wild-type strain and from the CEM1 strain was resolved by PFGE. The ethidium-bromide-stained gel showed the intact chromosomal DNA ( $2 \cdot 2 \mathrm{Mb}$ in size) for both strains; no signs of detectable plasmid were observed even when a higher amount of total DNA was added to the wells (Fig. 5a). Southern-blot analysis using the transposon-specific probe revealed a strong hybridizing signal only for the chromosomal DNA of P. putida CEM1 (Fig. 5b). Thus, the transposon-tagged cueAR operon was identified as being located within the chromosome.

\section{Loss of cueAR function and copper sensitivity}

The growth of the wild-type strain and of the CEM1 strain in the presence of varying concentrations of copper was compared. As shown in Fig. 6, both strains had comparable growth rates up until the $0.5 \mu \mathrm{M}$ copper level, but the CEM1 strain started showing increasingly 


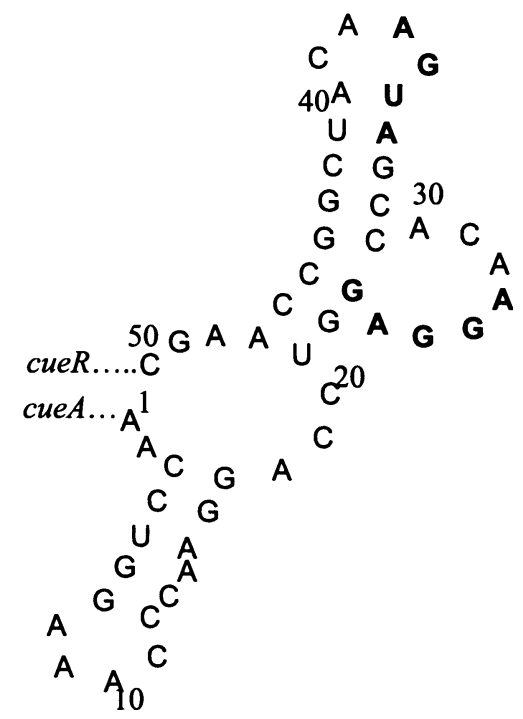

Fig. 4. Secondary structure of RNA. The stem-loop structure of the RNA sequence of the $50 \mathrm{bp}$ cueA-cueR junction is shown. The putative Shine-Dalgarno sequence (GAGGA) and the overlapping of the AUG and UGA sequences are indicated in bold.

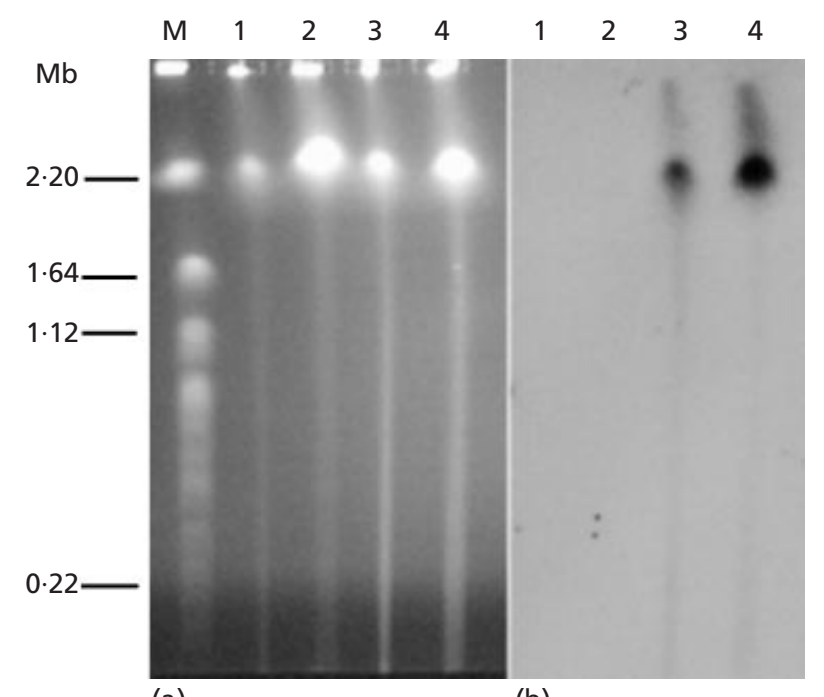

(a)

(b)

Fig. 5. Localization of cueAR by Southern hybridization. (a) Photograph of an ethidium-bromide-stained gel showing the total DNA resolved by PFGE. (b) Autoradiogram of a Southern blot done with the gel shown in (a). The gel was probed with digoxigenin-labelled gfp DNA. Lanes: M, DNA ladder (SigmaAldrich; Pulse marker $0.23-2 \cdot 2 \mathrm{Mb}$ ); 1, P. putida wild-type strain, with $0.5 \mu \mathrm{g}$ DNA added to the well; $2, P$. putida wildtype strain, with $15 \mu \mathrm{g}$ DNA added to the well; $3, P$. putida CEM1, with $0.5 \mu \mathrm{g}$ DNA added to the well; 4 , P. putida CEM1, with $13 \mu \mathrm{g}$ DNA added to the well.

slower growth in the presence of 3-30 $\mu \mathrm{M}$ extracellular copper. When strain CEM1 was grown in the presence of $100 \mu \mathrm{M}$ extracellular copper there was no detectable increase in its growth (Fig. 6). The wild-type strain exhibited comparable growth rates in all of the sub-MIC copper concentrations tested. The above results indicate that the cueAR mutation in strain CEM1 led to decreased copper tolerance.

The effect of the cueAR mutation on the rate of intracellular copper accumulation was studied in growth medium supplemented with $3 \mu \mathrm{M}$ copper (Fig. 7). This concentration of copper was chosen as it was the lowest level at which the growth of CEM1 showed significant retardation (Fig. 6). At $0 \mathrm{~h}$, the CEM1 cells contained $38 \mu \mathrm{g} \mathrm{Cu}$ (g dry weight cells) ${ }^{-1}$, whereas the wild-type cells had $24 \cdot 5 \mu \mathrm{g} \mathrm{Cu}$ (g dry weight cells) ${ }^{-1}$. Over the time course of the study, the CEM1 cells consistently accumulated higher levels of intracellular copper than the wildtype cells (Fig. 7). After $4 \mathrm{~h}$ of growth in coppersupplemented medium, a maximum mean difference of $55 \mu \mathrm{g} \mathrm{Cu}$ (g dry weight cells) ${ }^{-1}$ between the wild-type and the CEM1 strain was observed. This time period with its highest level of copper accumulation for CEM1 is in agreement with the results of the growth studies done at $3 \mu \mathrm{M}$ copper shown in Fig. 6, where the sensitivity of the CEM1 strain became apparent from $4 \mathrm{~h}$ onwards. At $6 \mathrm{~h}$, the copper contents in the two strains showed less difference (Fig. 7). Mean intracellular copper levels after $8 \mathrm{~h}$ of growth in the presence of copper were comparable in the two strains studied (Fig. 7), although their growth rates were significantly different (Fig. 6). Therefore, increased intracellular copper accumulation in CEM1 strongly suggests that the cueA-encoded P-type ATPase is involved in the copper export process.

\section{Complementation of the cueAR mutation}

The transposon insertion within cueA of the cueAR operon would have also affected the function of cueR. Therefore, the MICs of copper were determined for the CEM1 strain containing the constructs pGBcueAR, pGBcueA or pGBcueR (Fig. 1b). When inserted into CEM1, the pGBcueAR construct fully restored copper tolerance to CEM1 to the wild-type level $(\mathrm{MIC}=$ $400 \mu \mathrm{M})$. Similarly, when pGBcueA was inserted into CEM1 it also restored copper tolerance in this strain to a level comparable to that of the wild-type $(\mathrm{MIC}=$ $375 \mu \mathrm{M})$. Interestingly, pGBcueR restored the MIC of copper to $275 \mu \mathrm{M}$ when it was inserted into CEM1. It is noteworthy that unlike the pGBcueAR and pGBcueA constructs that included the native promoter, the expression of CueR from the pGBcueR construct was through the lac promoter. This makes the transcription of cueR from pGBcueR independent of any effects caused by varying copper concentrations. CEM1 (pGBcueAR) was tested in more detail for its ability to grow in varying concentrations of extracellular copper $(0-100 \mu \mathrm{M})$ that had been added to liquid MGY medium (Fig. 6). At all of the copper concentrations used in the experiments, the growth of the wild-type strain and of the CEM1(pGBcueAR) strain was comparable. In summary, the pGBcueAR construct fully restored the wildtype phenotype in strain CEM1, and the pGBcueR construct partially restored the wild-type phenotype. 


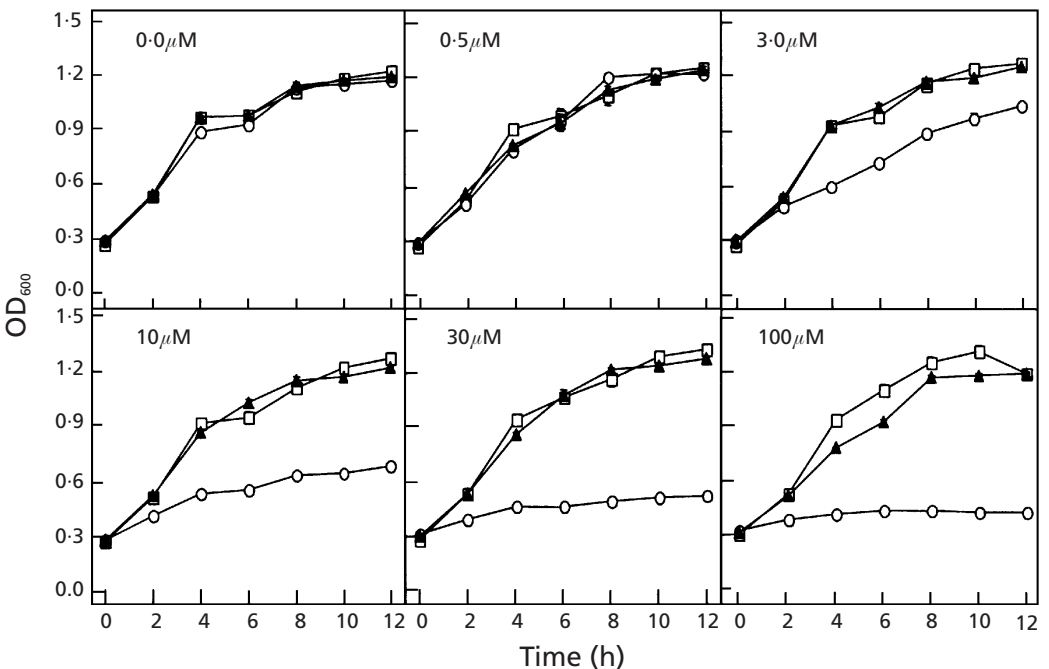

Fig. 6. Copper sensitivity of $P$. putida strains. The $P$. putida wild-type ( $\square$ ), mutant CEM1 $(O)$ and CEM1(pGBcueAR) (A) strains were grown in MGY broth. When an $\mathrm{OD}_{600}$ value of 0.32 was reached, $0-100 \mu \mathrm{M}$ copper sulphate was added to the growth medium and bacterial growth was monitored over a $12 \mathrm{~h}$ time period. Each data point is based on the mean of four replicates. The standard error was too small to be seen in most cases.

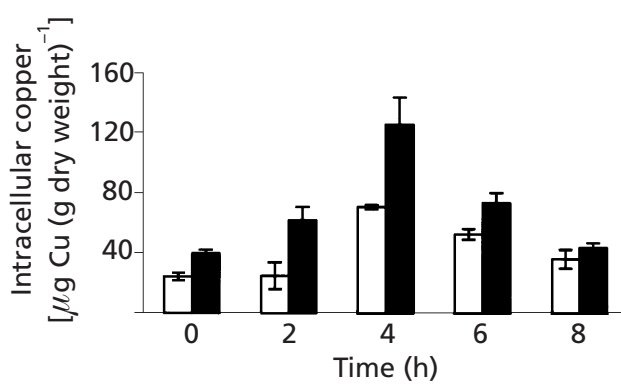

Fig. 7. Intracellular accumulation of copper in $P$. putida cells. The wild-type $(\square)$ and CEM1 ( $\square$ ) strains were grown in MGY medium to an $\mathrm{OD}_{600}$ value of 0.32 . The amount of intracellular copper was then estimated by atomic absorption spectrophotometry at different time points after the addition of $3 \mu \mathrm{M}$ copper sulphate to the medium.

\section{Regulation of cueAR expression}

Accumulation of GFP was used to study the expression of the cueAR operon, which was facilitated by the transcriptional fusion created by the fusion of miniTn $5:: g f p$ with cueA (cueA::gfp). Visualization of GFP expression in strain CEM1 under confocal laser microscopy showed increasing amounts of GFP fluorescence produced when the strain was grown in medium supplemented with $0-10 \mu \mathrm{M}$ copper (Fig. 8a). At higher concentrations of copper (up until $50 \mu \mathrm{M}$ ), no further increase in fluorescence was visible (data not shown). No auto-fluorescence of the wild-type cells was observed (Fig. 8a). It is noteworthy that a basal level of fluorescence was seen even when copper was not added to the growth medium. The relative amounts of fluorescence of GFP from whole cells of CEM1 and CEM1(pGBcueR) grown in the presence of varying levels of copper $(0-60 \mu \mathrm{M})$ was measured by flow cytometry. Accumulation of GFP in CEM1 was dose-dependent from 0 to $30 \mu \mathrm{M}$ copper (Fig. 8b). At the point of maximal induction the mean level of cueA::gfp expression was twofold higher (11.59) than the background level when the cells were grown without copper $(5 \cdot 28)$. In comparison to the CEM1 cells, GFP production in the CEM1(pGBcueR) cells showed a higher response to copper. The above results clearly indicate that the cueAR operon is regulated by copper and that CueR is a positive regulator of this operon.

\section{DISCUSSION}

In the present work, we have characterized an operon, cueAR, in $P$. putida which consists of two genes, one of which encodes a P1-type ATPase (cueA) and one of which encodes the $c u e A$ regulator $(c u e R)$ that belongs to the MerR family of proteins. To the best of our knowledge, none of the previously characterized genes encoding copper-transport proteins are organized in this manner. For example, other characterized coppertransport ATPase operons that consist of two genes, such as the copAP operons of Helicobacter spp. (Bayle et al., 1998) and the atkYB operon of Lactobacillus sakei (Stentz et al., 2000), do not have MerR-type helix-turnhelix regulators. In the cueAR region, a homologue of the recently published Streptococcus copZ regulator (Vats \& Lee, 2001), copP, is present. However, the threegene operon in Streptococcus, namely copYAZ, encodes a regulator similar to that encoded by the $\operatorname{cop} Y Z A B$ copper-transport system of Enterococcus - this regulator is not of the MerR type. The copper-transport genes most similar to those of cueAR of $P$. putida are copA and cueR of Escherichia coli (Rensing et al., 2000; Outten et al., 2000; Stoyanov et al., 2001). However, the organization of these genes in E. coli is once again different as the two genes are separated by two unrelated genes. Two contiguous genes encoding a MerR-type regulator and a P-type ATPase involved in cadmium resistance were recently reported for $P$. putida, but these genes were divergently transcribed (Lee $e t$ al., 2001). Therefore, to the best of our knowledge, the organization of the genes in the copper-transport system of the $P$. putida strain studied here is unique among the ATPase-encoding copper-transport systems characterized so far. 
(a)
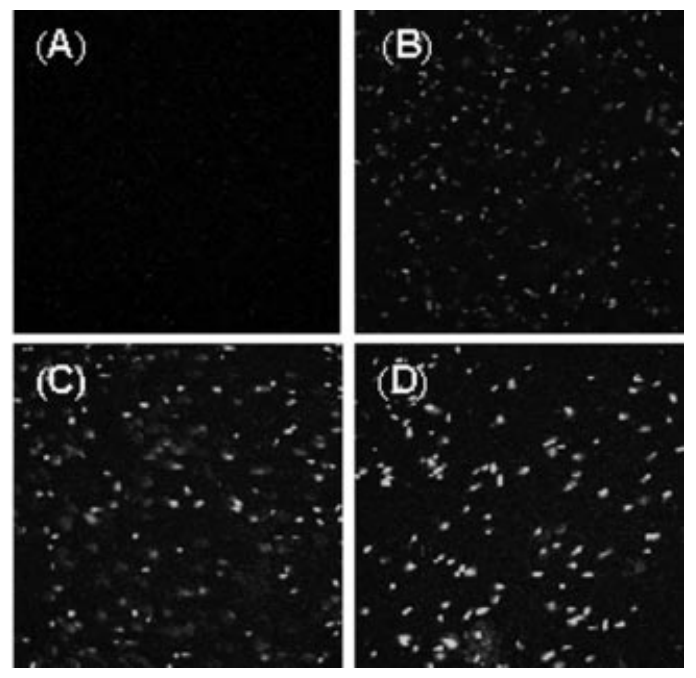

(b)

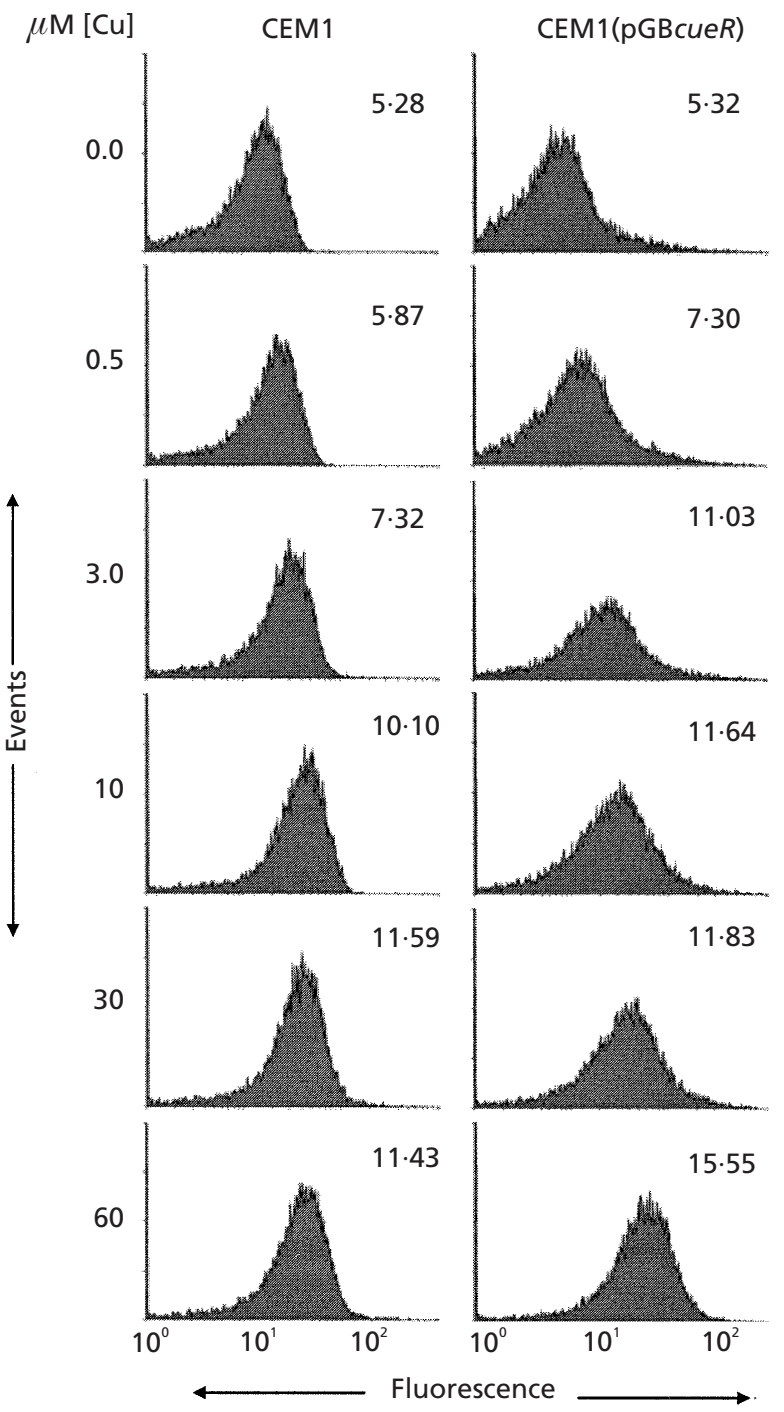

Many Pseudomonas strains have been reported to be tolerant to varying levels of copper (Cooksey et al., 1990; Vargas et al., 1995; Bender \& Cooksey, 1986). In one report, based on the screening of 20 Pseudomonas strains for copper resistance, eight strains of $P$. syringae pv. tomato were placed into a copper-sensitive group because of their lower tolerance to copper sulphate when grown in MGY medium supplemented with this compound (MICs of $0.4-0.6 \mathrm{mM}$ ). All eight of these strains contained plasmids (Bender \& Cooksey, 1986). Although the genes responsible for copper tolerance, and their localization, were not characterized for the eight strains, the range of their copper tolerance would place the wild-type strain studied here in the coppersensitive group (MIC $=0.4 \mathrm{mM}$ ). Furthermore, in those strains that are resistant to higher levels of copper, the determinants of copper tolerance have been shown to encode either copper-binding and sequestering proteins or copper oxidases (Mellano \& Cooksey, 1988; Cooksey et al., 1900; Cervantes \& Gutierrez-Corona, 1994). Therefore, the present study is a report of the involvement of P1-type ATPase in conferring copper tolerance to a copper-sensitive group of Pseudomonas strains. Additionally, the transporter-encoding cueAR operon proved to be located in the chromosome, in contrast to the plasmid localization of many of the copper tolerance determinants of other pseudomonads (Mellano \& Cooksey, 1988; Stall et al., 1986; Bender \& Cooksey, 1986).

cueAR is likely to play a significant role in copper homeostasis. Firstly, the wild-type strain has a relatively low level of tolerance $(\mathrm{MIC}=0.4 \mathrm{mM})$ in the context of copper resistance in bacteria. Secondly, as shown by growth studies, the loss of cueAR leads to reduced tolerance that is apparent at levels as low as $3 \mu \mathrm{M}$ extracellular copper (Fig. 6). This observation is in agreement with the earlier understanding that microorganisms usually satisfy their copper requirement in the $1-10 \mu \mathrm{M}$ range (Cervantes \& Gutierrez-Corona, 1994); thus, cueAR putatively functions even within the range of copper levels required by the cells. Therefore, we argue that the cueAR operon in P. putida is likely to be involved in copper homeostasis, rather than conferring resistance to high levels of copper. Furthermore, the increase followed by a decline in the intracellular copper contents observed for both the wild-type and the CEM1 strain at their sub-MIC (3 $\mu \mathrm{M})$ level (Fig. 7)

Fig. 8. Expression of cueA::gfp when $P$. putida cells were grown in the presence of different concentrations of copper. (a) Fluorescence of whole cells was observed under a confocal laser microscope. The cells were excited with a $488 \mathrm{~nm}$ laser and fluorescence was detected at $510 \mathrm{~nm}$. (A) Wild-type cells; (B) CEM1 grown in the presence of $0 \mu \mathrm{M}$ copper; (C) CEM1 grown in the presence of $3 \mu \mathrm{M}$ copper; (D) CEM1 grown in the presence of $10 \mu \mathrm{M}$ copper. (b) GFP production in whole cells of CEM1 and CEM1(pGBcueR), as measured by flow cytometry. The strains were grown in $M G Y$ for $4 \mathrm{~h}$ to an $\mathrm{OD}_{600}$ value of 0.32 . Different concentrations of copper were then added to the cultures and the level of fluorescence was measured. Each histogram was obtained with 30000 events. The geometric mean value for the histograms is given at the top of each plot. 
suggests more than one mechanism to be involved in copper homeostasis in P. putida. Although CueAmediated copper transport is one mechanism involved in copper homeostasis in $P$. putida, the nature of other copper-homeostasis mechanisms operating in this strain is as yet unknown. In the genus Pseudomonas, and its related genus Xanthomonas, cop genes and their homologues encoded by the chromosome have been reported (Cooksey et al., 1990; Lim \& Cooksey, 1993; Lee et al., 1994; Vargas et al., 1995). These genes impart relatively low levels of copper tolerance upon strains when compared to those in a $P$. syringae strain carrying plasmid-borne cop genes (Mellano \& Cooksey, 1988). It is noteworthy that unlike the cueA gene reported here, these plasmid-borne cop genes do not encode ATPases. In the wild-type strain studied here, which has a low level of copper tolerance, one or more of the above chromosomal genes could, therefore, possibly be present. In our study, the MIC results confirm that the loss of cueAR results in a sixfold reduction in copper tolerance; this intolerance is only to copper and not to the other metals tested (namely mercury, silver, zinc, iron, nickel, cobalt and cadmium). Moreover, it is evident that the sensitivity of strain CEM1 to copper is due to increased accumulation of this metal. Therefore, these results suggest that cueAR is specific to copper transport and CueA functions as an exporter of copper.

Gene-expression analyses, based on the cueA::gfp transcriptional fusion, indicate that the cueAR operon is autoregulated, as well as being regulated by copper. The cueAR promoter carries cis-signals (a cop box and other inverted repeats) known to bind MerR-like helixturn-helix proteins such as CueR. Moreover, CueR contains putative metal-binding residues at its $\mathrm{C}$ terminus. When cueR is expressed in a plasmid with the lac $Z$ promoter that is non-responsive to copper, the expression of the native chromosomal cueAR promoter in strain CEM1 gets upregulated in a copper-dependent manner. CueR is highly similar to the Tn501 mercuryoperon regulator MerR, and proteins of this class are known to become competent transcriptional activators upon metal binding (Lund \& Brown, 1987; Outten et al., 2000; Stoyanov et al., 2001). Therefore, it is clear that CueR positively regulates the function of its own promoter. Additionally, as was shown in the $c u e A:: g f p$ expression studies with the CEM1 strain and the cueRcomplemented strain, the expression of GFP varies with respect to the extracellular concentrations of copper. Thus, it is evident that the cueAR operon is regulated by extracellular copper levels via CueR.

There may be partial functional redundancy of both cueR and cueA. The increased copper tolerance of the CEM1(pGBcueR) strain indicates that CueR alone is able to partially alleviate copper toxicity. In E. coli, it is known that the copA regulator CueR regulates the expression of another gene, cueO, which is also involved in copper tolerance (Outten et al., 2000; Grass \& Rensing, 2001). Perhaps an, as yet, undiscovered orthologue of CueO might exist in $P$. putida that may explain the partial redundancy of cueA function. With regard to
P. putida CueR, the increasing GFP fluorescence obtained when CEM1 was grown in the presence of increasing levels of copper shows that the cueAR promoter responds to other transcriptional activators in the absence of CueR. Additionally, pGBcueA introduced into strain CEM1, in the absence of intact CueR, is able to restore copper tolerance levels to nearly equal those of the wild-type strain. To our knowledge, such regulation of a P1-type ATPase operon by multiple activators needs to be studied in more detail.

In addition to being under transcriptional control, cueAR function may also be under post-transcriptional control. The cueA-cueR junction shows features characteristic of translational coupling (McCarthy \& Gualerzi, 1990), with a -1 frameshift at the cueA-cueR junction and the placement of a Shine-Dalgarno sequence as part of a stable RNA hairpin loop structure (Fig. 4) that could prevent independent translation. Examples of tightly controlled systems created by the formation of a secondary RNA structure in the inter-cistronic boundary have been demonstrated in many cases, including that of the nifLA genes of Klebsiella pneumoniae, where inappropriate levels of NifA synthesis are avoided (Goventes et al., 1996). It is, therefore, tempting to speculate that translational coupling could be involved in cueAR regulation, which makes this operon an interesting candidate for future studies.

\section{ACKNOWLEDGEMENTS}

We thank the Environmental Engineering Laboratory, Department of Civil Engineering, and the Analytical Chemistry Laboratory, Department of Chemistry, of the National University of Singapore for providing their atomic absorption spectrophotometry facility. We thank Mark Kingsley, PNNL, USA, for providing the wild-type Pseudomonas strain. V.A. wishes to thank the National University of Singapore for the award of his research scholarship.

\section{REFERENCES}

Bayle, D., Wangler, S., Weitzenegger, T., Steinhilber, W., Volz, J., Przybylski, M., Schafer, K. P., Sachs, G. \& Melchers, K. (1998). Properties of the P-type ATPases encoded by the copAP operons of Helicobacter pylori and Helicobacter felis. J Bacteriol 180, 317-329.

Beard, S. J., Hashim, R., Membrillo-Hernandez, J., Hughes, M. N. \& Poole, R. K. (1997). Zinc(II) tolerance in Escherichia coli K-12: evidence that the $z n t A$ gene (o732) encodes a cation transport ATPase. Mol Microbiol 25, 883-891.

Bender, C. L. \& Cooksey, D. A. (1986). Indigenous plasmids in Pseudomonas syringae pv. tomato: conjugative transfer and role in copper resistance. J Bacteriol 165, 534-541.

Bloemberg, G. V., O'Toole, G. A., Lugtenberg, B. J. J. \& Kolter, R. (1997). Green fluorescent protein as a marker for Pseudomonas spp. Appl Environ Microbiol 63, 4543-4551.

Buffoni, F. \& Ignesti, G. (2000). The copper-containing amine oxidases: biochemical aspects and functional role. Mol Genet Metab 71, 559-564.

Bull, P. C. \& Cox, D. W. (1994). Wilson disease and Menkes disease: new handles on heavy-metal transport. Trends Genet 10, 246-252. 
Camakaris, J., Voskoboinik, I. \& Mercer, J. F. (1999). Molecular mechanisms of copper homeostasis. Biochem Biophys Res Commun 261, 225-232.

Casse, F., Boucher, C., Julliot, J. S., Michel, M. \& Dénairé, I. (1979). Identification and characterization of large plasmids in $\mathrm{Rhi}$ zobium meliloti using agarose gel electrophoresis. J Gen Microbiol 113, 229-242.

Cervantes, C. \& Gutierrez-Corona, F. (1994). Copper resistance mechanisms in bacteria and fungi. FEMS Microbiol Rev 14, 121-137.

Cooksey, D. A., Azad, H. R., Cha, J. \& Lim, C. (1990). Copper resistance gene homologs in pathogenic and saprophytic bacterial species from tomato. Appl Environ Microbiol 56, 431-435.

Dameron, C. T. \& Harrison, M. D. (1998). Mechanisms of protection against copper toxicity. Am J Clin Nutr 67 (Suppl. 5), 1091s-1097s.

Degtyarenko, K. (2000). Bioinorganic motifs: towards functional classification of metalloproteins. Bioinformatics 16, 851-864.

Govantes, F., Molina-Lopez, J. A. \& Santero, E. (1996). Mechanism of coordinated synthesis of the antagonistic regulatory proteins NifL and NifA of Klebsiella pneumoniae. J Bacteriol 178, 6817-6823.

Grass, G. \& Rensing, C. (2001). Genes involved in copper homeostasis in Escherichia coli. J Bacteriol 183, 2145-2147.

Hofacker, L., Fontana, W., Stadler, P. F., Bonhoeffer, L. S., Tacker, M. \& Schuster, P. (1994). Fast folding and comparison of RNA secondary structures. Monatsh Chem 125, 167-188.

Lee, Y. A., Hendson, M., Panopoulos, N. J. \& Schroth, M. N. (1994). Molecular cloning, chromososmal mapping, and sequence analysis of copper resistance genes from Xanthomonas campestris pv. juglandis: homology with small blue copper proteins and multicopper oxidase. J Bacteriol 176, 173-188.

Lee, S. W., Glickmann, E. \& Cooksey, D. A. (2001). Chromosomal locus for cadmium resistance in Pseudomonas putida consisting of a cadmium-transporting ATPase and a MerR family response regulator. Appl Environ Microbiol 67, 1437-1444.

Lim, C. K. \& Cooksey, D. A. (1993). Characterization of chromosomal homologs of the plasmid-borne copper resistance operon of Pseudomonas syringae. J Bacteriol 175, 4492-4498.

Lund, P. A. \& Brown, N. L. (1987). Role of the merT and merP gene products of transposon Tn501 in the induction and expression of resistance to mercuric ions. Gene 52, 207-214.

Lutsenko, S. \& Kaplan, J. H. (1995). Organization of P-type ATPases: significance of structural diversity. Biochemistry 34, 15607-15613.

McCarthy, J. E. G. \& Gualerzi, C. (1990). Translational control of prokaryotic gene expression. Trends Genet 6, 78-85.

Mellano, M. A. \& Cooksey, D. A. (1988). Induction of copper resistance operon from Pseudomonas syringae. J Bacteriol 170, 4399-4401.

Odermatt, A. \& Solioz, M. (1995). Two trans-acting metalloregulatory proteins controlling expression of the copper-ATPases of Enterococcus hirae. J Biol Chem 270, 4349-4354.

Odermatt, A., Suter, H., Krapf, R. \& Solioz, M. (1993). Primary structure of two P-type ATPases involved in copper homeostasis in Enterococcus hirae. J Biol Chem 268, 12775-12779.

Outten, F. W., Outten, C. E., Hale, J. \& O’Halloran, T. V. (2000). Transcriptional activation of an Escherichia coli copper efflux regulon by the chromosomal MerR homologue, CueR. J Biol Chem 275, 31024-31029.

Pillai, B. V. S. \& Swarup, S. (2002). Elucidation of flavonoid catabolism pathway in Pseudomonas putida PML2 by comparative metabolic profiling. Appl Environ Microbiol 68, 143151.

Rensing, C., Fan, B., Sharma, R., Mitra, B. \& Rosen, B. P. (2000). CopA: an Escherichia coli $\mathrm{Cu}(\mathrm{I})$-translocating P-type ATPase. Proc Natl Acad Sci US A 97, 652-656.

Sambrook, J., Fritsch, E. F. \& Maniatis, T. (1989). Molecular Cloning: a Laboratory Manual, 2nd edn. Cold Spring Harbor, NY : Cold Spring Harbor Laboratory.

Solioz, M. \& Vulpe, C. (1996). CPx-type ATPases: a class of P-type ATPases that pump heavy metals. Trends Biochem Sci 21, 237-241.

Stall, R. E., Loschke, D. C. \& Jones, J. B. (1986). Linkage of copper and avirulence loci on a self-transmissible plasmid in Xanthomonas campestris pv. vesicatoria. Phytopathology 76, 240-243.

Stanier, R. Y., Palleroni, N. J. \& Doudoroff, M. (1966). The aerobic pseudomonads : a taxonomic study. J Gen Microbiol 43, 159-271.

Stentz, R., Loizel, C., Malleret, C. \& Zagorec, M. (2000). Development of genetic tools for Lactobacillus sakei: disruption of the $\beta$-galactosidase gene and use of lac $Z$ as a reporter gene to study regulation of the putative copper ATPase, AtkB. Appl Environ Microbiol 66, 4272-4278.

Stoyanov, J. V., Hobman, J. L. \& Brown, N. L. (2001). CueR (YbbI) of Escherichia coli is a MerR family regulator controlling expression of the copper exporter CopA. Mol Microbiol 39, 502-511.

Suarez, A., Guttler, A., Stratz, M., Staendner, L. H., Timmis, K. N. \& Guzman, C. A. (1997). Green fluorescent protein-based reporter systems for genetic analysis of bacteria including monocopy applications. Gene 196, 69-74.

Syn, C. K. C. \& Swarup, S. (2000). A scalable protocol for the isolation of large-sized genomic DNA within an hour from several bacteria. Anal Biochem 278, 86-90.

Tetaz, T. J. \& Luke, R. K. J. (1983). Plasmid-controlled resistance to copper in Escherichia coli. J Bacteriol 154, 1263-1268.

Tom-Petersen, A., Hosbond, C. \& Nybroe, O. (2001). Identification of copper-induced genes in Pseudomonas fluorescens and use of a reporter strain to monitor bioavailable copper in soil. FEMS Microbiol Ecol 38, 59-67.

Vargas, E., Gutierrez, S., Ambriz, M. E. \& Cervantes, C. (1995). Chromosome-encoded inducible copper resistance in Pseudomonas strains. Antonie Leeuwenhoek 68, 225-229.

Vats, N. \& Lee, S. F. (2001). Characterization of a copper-transport operon, copYAZ, from Streptococcus mutans. Microbiology 147, 653-662.

Vieira, J. \& Messing, J. (1982). The pUC plasmids, an M13mp7derived system for insertion mutagenesis and sequencing with synthetic universal primers. Gene 19, 259-268.

Weissman, Z., Berdicevsky, I., Cavari, B. \& Kornitzer, D. (2000). The high copper tolerance of Candida albicans is mediated by a P-type ATPase. Proc Natl Acad Sci U S A 97, 3520-3525.

Yang, C. H., Azad, H. R. \& Cooksey, D. A. (1996). A chromosomal locus required for copper resistance, competitive fitness, and cytochrome $c$ biogenesis in Pseudomonas fluorescens. Proc Natl Acad Sci US A 93, 7315-7320.

Received 15 February 2002; revised 4 May 2002; accepted 24 May 2002. 